\title{
Mobile-based SIWES Placement Recommendation System (A Case Study of Nigerian Universities)
}

\author{
Orimoloye Segun Michael \\ Department of Computer Science \\ Adekunle Ajasin University \\ Akungba Akoko, Ondo State \\ Nigeria
}

\author{
Kolawole Blessing Oluwatosin \\ Department of Computer Science \\ Adekunle Ajasin University \\ Akungba Akoko, Ondo State \\ Nigeria
}

\begin{abstract}
The perennial problem students of higher institutions of learning in Nigeria face on an annual basis in finding suitable placements based on their locational and organizational preferences for the Mandatory Industrial training which varies from 6 months to a year cannot be overemphasized. They resort to manual means of seeking such placements themselves. Many end up frustrated and eventually settle for placements where they get minimal relevant training which in itself defeats the aim of the SIWES programme, established to help bridge the gap between the industry and the classroom. Unfortunately, no effort has been made prior to this work to come up with an automated system that assist in ameliorating this problem. The closest has been just to monitor the activities of the students after they must have commenced the programme. This work therefore proposes a Mobile based system that would be deployed and used on-the-go, automatically recommending suitable organizations based on the discipline and locational preferences of the prospective students. Data on suitable organizations on a locational basis was obtained from the SIWES unit of the research host institutions, based on previous Industrial trainings/internships was used to populate the database from which the mobile application does recommendations.
\end{abstract}

\section{Keywords}

Framework, Mobile, SIWES, Industrial Training, Placement, Recommendation

\section{INTRODUCTION}

The existence of a gap between the theoretical principles and real practical in various fields such as engineering and technology, science, agriculture, medicine, management and other professional educational programs in Nigeria tertiary institution poses a great need to expose students to machines and equipment, professional work methods and ways of safeguarding the work area and workers in industries and other organizations in order to improve the practical skills of students.

Knowing fully well that Training is a key factor in enhancing the efficiency and expertise of the workforce and no society can achieve meaningful progress without encouraging its youth to acquire necessary practical skills that will enable them to harness available resources to meet the needs of society- an innovative phenomenon in human resources development and training in Nigerian tertiary institutions by the industrial training fund (ITF). This innovative phenomenon was called The Student Industrial Work Experience Scheme (SIWES) otherwise referred to as Industrial Training (IT).
The Student Industrial Work Experience Scheme (SIWES) was initiated in the year 1973 by the industrial training fund (ITF). It is a Tri-partite programme involving Students, Universities and Industries. It is funded by the federal government of Nigeria and jointly coordinated by the ITF and the Nigerian Universities Commission (NUC). According to it is a skill training programme designed to expose and prepare students of post-secondary schools (tertiary institutions) to the industrial work situation they are likely to meet after graduation.

A mobile-based SIWES placement survey system can be described in so many ways, but owing to the perspective of this study, it is a mobile system that can be installed and run on different mobile platforms (IOS, Android, Windows Phone, etc.) and different mobile devices (smart phones and tablets) but are written with web technologies. This system (Mobile-based SIWES placement survey system) would be a hybrid application that run inside a native container, and leverage the device's browser engine (but not the browser) to render the HTML and process the JavaScript locally. This approach is important so as not to make the system platform dependent.

It is a system with the sole aim of bringing vast information (about organizations of high relevance to students' courses of study) and resources available from many sources to many users (SIWES students) in an effective manner. It provides mobile services that will enhance SIWES students' easier means of fetching (to have an online means of getting) organizations of high relevance to their courses of study, applications to selected organizations and as well giving feedbacks of acceptance from various organizations.

\section{STATEMENT OF THE PROBLEM}

Right from onset, survey or search for students' places of attachment for SIWES program has always been done manually. In this case, students going for SIWES programme have no option but to leave school (or sometimes their various homes) to several parts of the country in search for a location where they could carry out their SIWES programme during the on-going semester. This is because they of course prefer to have a place of attachment before the commencement of the next semester (the semester in which the programme is to be observed) bearing in mind that late resumption to their places of attachment will attract a penalty which will tell on their report. This they sometimes do even without having a target organization hence, sometimes applying at organizations not relevant to their field of study which might then lead to little or no experience gained. Consider a Computer science student having his or her 6 months training in a phone repair shop or even in a local government. This occurs most times either because some are not acquainted with the various organizations in the country with activities that are of 
relevance to their field or at times because they do not have the opportunity to apply at such organizations (probably because of distance).

\subsection{Problem Description}

\section{Difficulties in finding firms for internship}

Some students search for placement even without having a target organization hence, sometimes applying at the organizations not relevant to their field of study which might then lead to little or no experience gained after spending much of transport fare.

\section{Difficulties in application due to distance barrier:}

Knowing fully well that not all firms in Nigeria have a corporate site where applicants can easily apply, sometimes students find it difficult to apply to those organizations even if they are of great relevance and importance to their field because of the distance from their present location to the organizations.

\section{Ineffective Organization Of Industrial Attachment:} It should be noted that the Student Industrial Work Experience Scheme (SIWES) programme was designed to familiarize trainee. This according to [10] is that the programme has taken short of expectation as a result of poor coordination between industries and training institution [3].

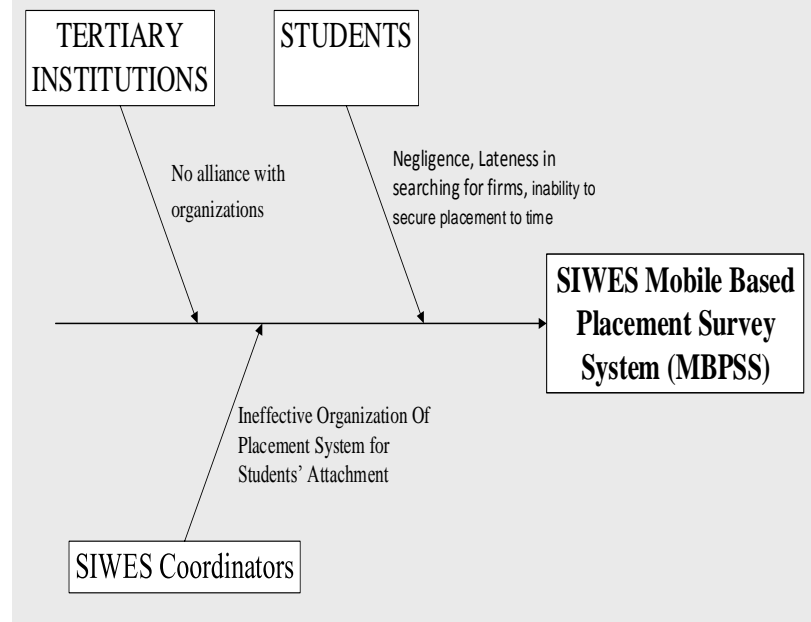

Figure 1: Ishikawa Diagram detailing the Problem Definition

\section{MOTIVATION FOR THE STUDY}

Generally in Nigeria, the system for which placement locations are sought for has always been manual thereby yielding an unsatisfactory result in the placement of SIWES students. We therefore proposed to embark on this research work in order to fully exploit the present technological advances to improve this process of SIWES placement by leveraging on the popularity of mobile technologies to provide a system that automatically recommends suitable placement for students embarking on Industrial training based on their preferred location and course of study.

\section{RELATED WORKS}

1. Emmanuel Adetiba, Victor O. Matthew et.al. "Development of e-SIWES portal: A Web based Platform for student Industrial Work Experience Scheme (SIWES) Management".
Aim: To develop a web-based Platform for student Industrial Work Experience Scheme (SIWES) Management that allows the manual task of carrying out SIWES activities and supervision/ assessment by lecturers and industries based supervisors.to be carried out using the personal computer and the internet.

Proposal's Scope and Strength: this work entailed using electronic medium to substitute area of manual task of carrying out SIWES activities and supervision/ assessment by lecturers and industries based supervisors.

Limitation: this study only covers supervision/assessment by lecturers and industries based supervisors' part of SIWES programme.

2. Mr. R J LAIRD, School of Engineering, University of Ulster. "Interactive Web based Placement Management - Principles and Practice using Online Placement University System (OPUS)".

Aim: to explore the use of the Internet to enable students and companies to manage the placement process with the active involvement of the Industrial Placement Coordinator.

Proposal's Scope and Strength: This involved the development of a unique web-based placement management system specifically by the placements practitioner and the software programmer to become OPUS (Online Placement University System) since autumn 2000. The basic system was able to manage the first cohort of engineering students into placement in 2002. Since these early basics the programme has been developed continuously as an open source product, now at version 4

3. Chijioke F. Ugwuanyi , Jonas U. Ezema. "Challenges of Students' Industrial Work Experience Scheme (SIWES) in Library and Information Science in the ICT Environment".

Aim: To explain the challenges of SIWES pertaining to the incorporation of ICT, the new development, to encourage effective services to users. Some of these developments, according to Ajidahun (2007), include automation and computers in libraries and other information systems.

Limitation: Practical works to proffer solutions to those challenges noted were not considered.

With this proposed system, the user may control their information, the provider may promote their opportunities, the student can take action to apply for any vacancy and the placements coordinator may control all features.

\section{SYSTEM MODELLING AND \\ ANALYSIS}

\subsection{The Existing System Model}

Models of the existing system help clarify what the existing system does and can be used as a basis for discussing its strengths and weaknesses. These then lead to requirements for the new system.

The existing system involves students' manual means of fetching an industry or firm as place of attachment. This system contains the students and the industries. This model is exemplified in Figure 1 above with the ISHIKAWA diagram. 


\subsection{The Proposed System}

For this study, emphasis shall be on representing the system with combination of different type of models that best suit the concept which are: the conceptual and interactive Model.

\subsubsection{Conceptual/Contextual Modelling}

This incorporates ethnographic methods for gathering data relevant to the proposed model via field studies, rationalizing workflows, and designing interfaces.

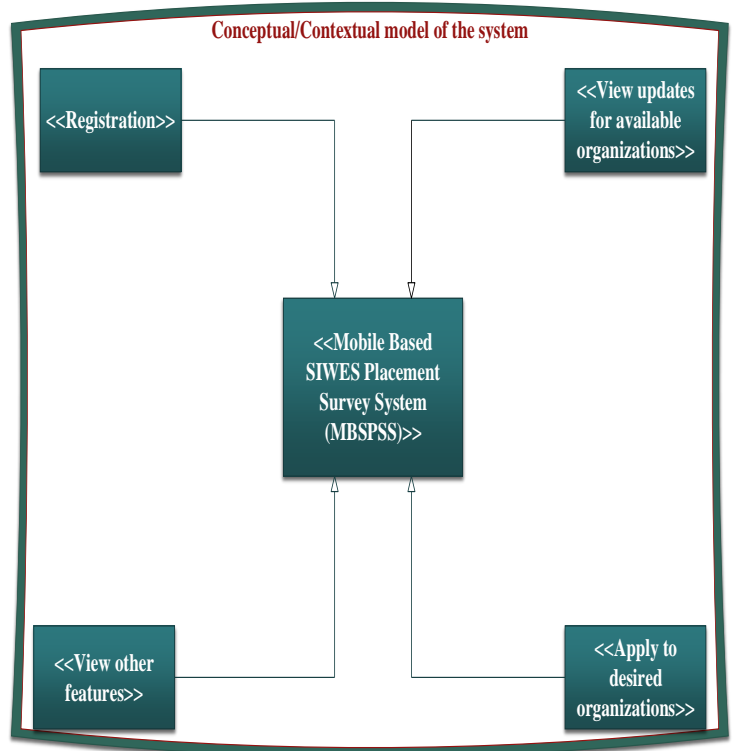

Figure 2: Conceptual/Contextual model of Proposed System

\subsubsection{Interaction modelling (Using Use-case)}

A subset of the model showing the goals of the users, interactions between the users and the system is depicted graphically below.

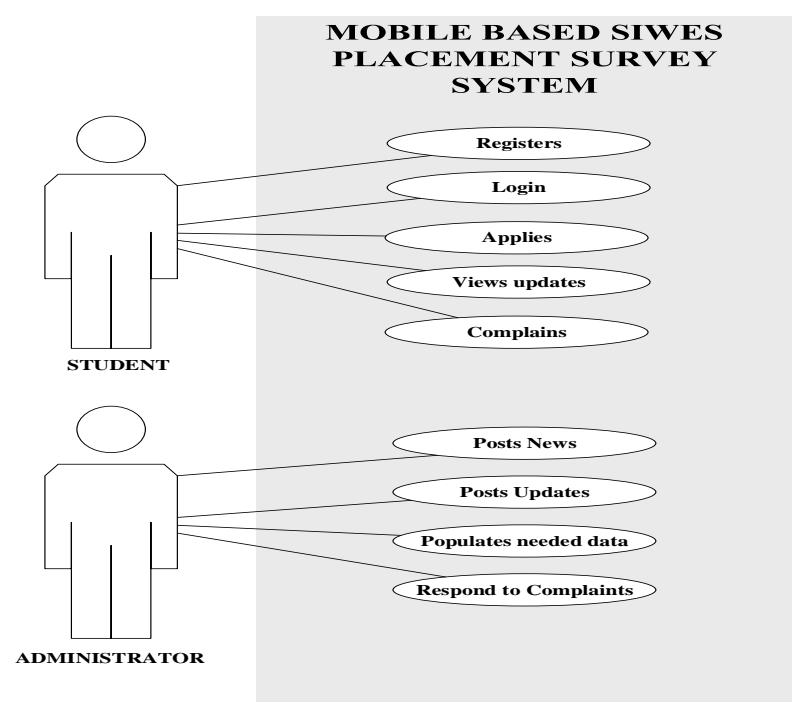

Figure 3: Use case diagram of Proposed System

\subsection{Proposed System Architecture}

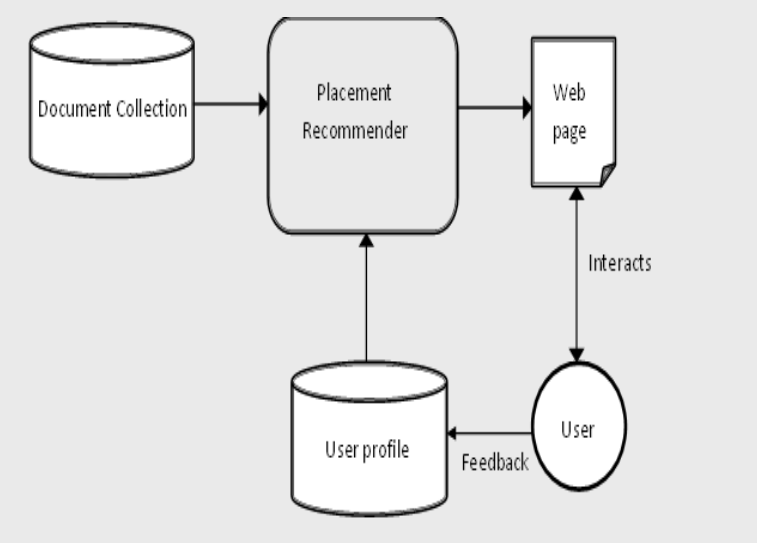

Figure 4: Proposed System Architecture

Series of documents about organizations are stored in the document collection database, the recommender supplies these organizations on the mobile application, users interacts with the mobile applications and their feedbacks are stored in the user profile table in the database. The details of the users are sent as feedback to the system.

\subsection{Justification for the Proposed System}

The Mobile-based SIWES Placement Recommendation system (MBSPRS) is developed to digitize all manual activities carried out by students during the course of the SIWES placement. These activities may be independent or inter-related for the user groups. The following are the functional requirements for the SIWES portal.

i. The administrator creates the profiles of students that are eligible to go for the SIWES program.

ii. The system generates a list of the students that are eligible to go for the SIWES program.

iii. The administrator populates the database with different suitable places of possible Industrial attachment/internship on a per-discipline basis. This information is obtained from a survey undertaken of reputable organizations that students who have undergone the scheme previously had their Industrial training.

iv. Students $\log$ in to the portal and are identified with unique matriculation number and password (registration number) as assigned by the school and as stored in the database.

v. Students view the announcements page (which is editable by the admin) and changes in companies and vacancies since their last login.

vi. Students can create their resume using varieties of styles and apply online to organizations by 'tagging' their resume (with an optional electronic 'covering letter') to the vacancy of their choice or by other directed methods as specified by the placement provider.

vii. Administrator creates a targeted help list for the students throughout their use of MBSPRS as the system recognizes their login. 
viii. Administrators provide facility for students to create their CV using varieties of styles and continue to have ownership of their data through editing at any time.

\section{SYSTEM DESIGN AND IMPLEMENTATION}

System design entails the various processes through which software requirements are translated into a "blueprint" for constructing MBSPRS. It identifies and itemizes the software components and their relationships according to the stated requirements and as well defines the components modules, interfaces and architecture of the system.

\subsection{Database Design}

The database system is designed to be implemented using MySQL stored procedures, and the database is built around the needs of the algorithm but at the same time maintaining the principles of legal database design.

Below are the database schemas for the various database files used.

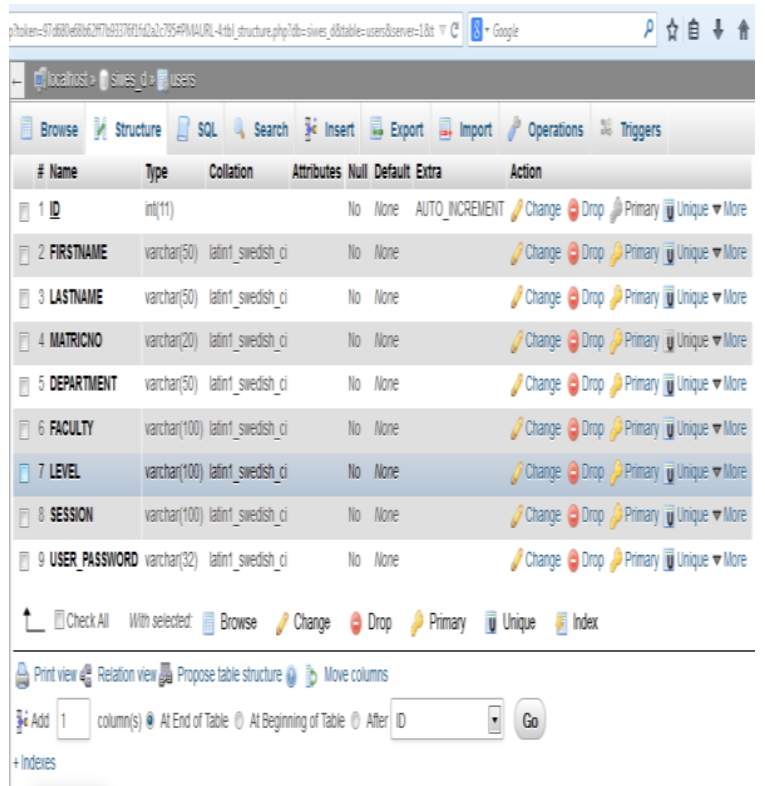

Figure 5: Registration/Sign up Database File

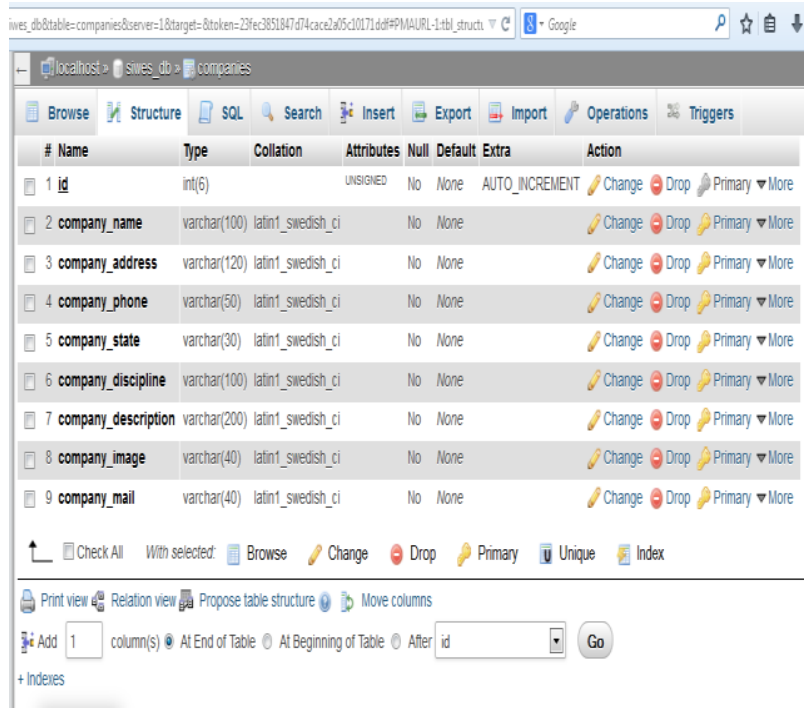

Figure 6: Company Details Database File

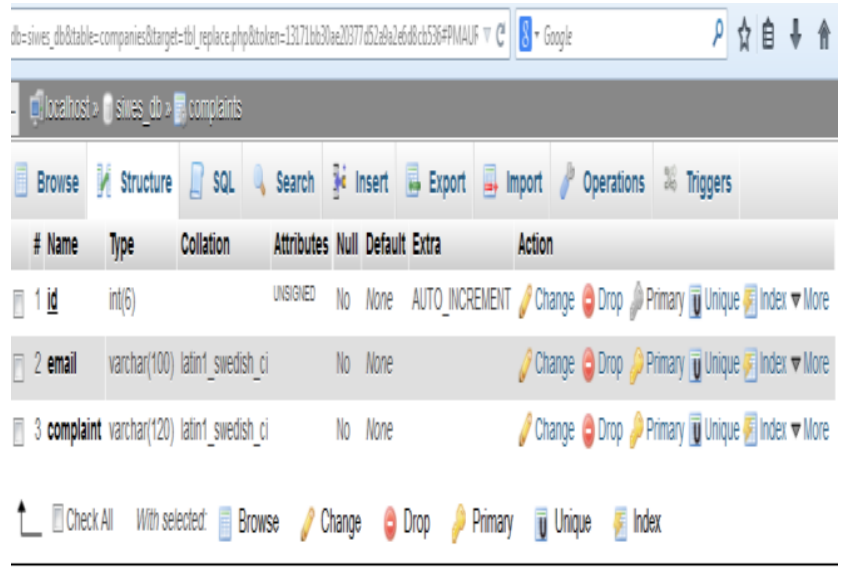

Figure 7: Complaints database file

\subsection{Program Module Specification} Registration/ Student Biodata

At this module, all the required documentations of the student are stored. Here, student's registration data is stored into the registration table. This module encompasses the data of students that are qualified to go for SIWES program.

\section{Login}

This module grants access to authorized users (the students, admin) to login into the system.

\section{Complaint}

This program module permit the students to log complain and also get response from the Admin.

\section{Compose}

This module allows the user to write letter, attach IT (Industrial Training) letters, and other needed files and then forward the letter to organization to which the students wants to apply

\section{Admin}

This module allows the Admin staff to get information across to the student.

\section{Contact us}

This program module enhances easy communication between the students and the SIWES unit. It provides contacts of the SIWES officer.

\subsection{Results}

\section{(i) Search module}

At this module, the users enter the search criteria (their field of study and the state they wish to search). On click on the search button list of companies in their available at the selected state is generated as shown in Fig 6.3.1 below

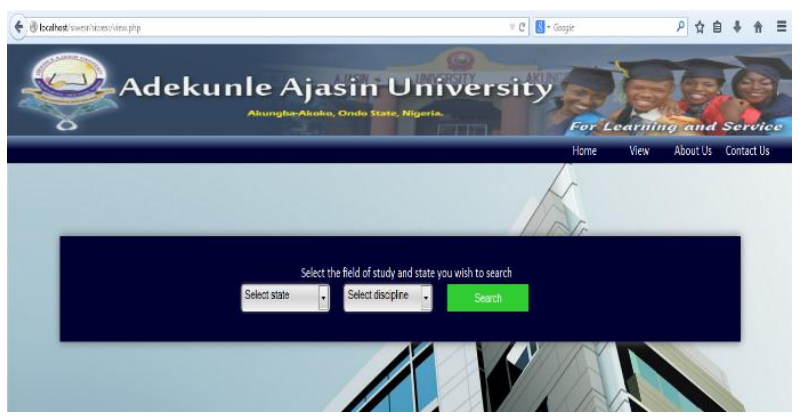

Figure 8: SIWES Placement Search page 
(ii) Application module

At this module the users (students) make their applications to several organizations after they have been recommended from the search operation in (i) above.

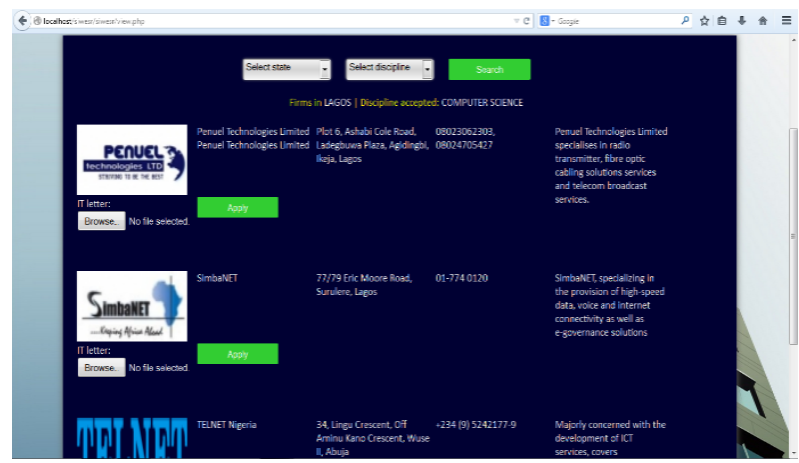

Figure 9: SIWES Placement Recommendation page

On click on browse, the user can attach IT letter, CV. On click on apply, the application is submitted to the mail of the selected organization

\section{(iii) The Administrator's module}

The administrator's Module allows the site administrator populate the site with information and also carrying different task varying from system settings to information management. The administrator's task include

1. Registration/ Modification of Organizations information

2. Management of Site Content

3. Responding to student's complaint/ FAQ

4. Collation of Various report such as

a. General Student Account information

b. List of Firms accommodating students etc.

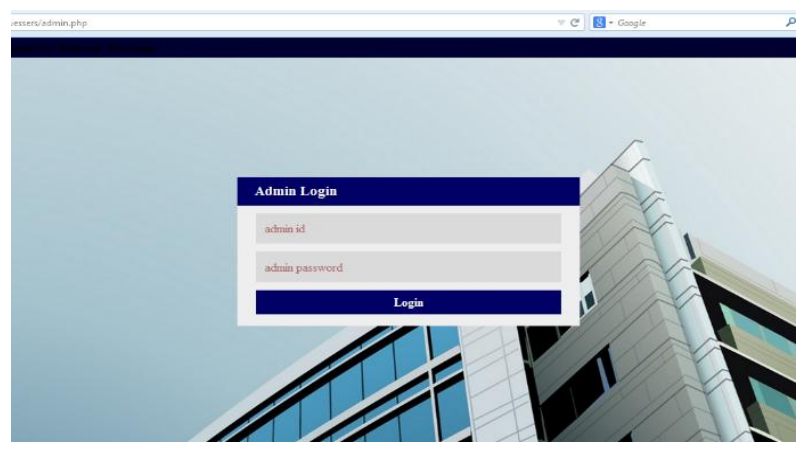

Figure 10: Admin Login page

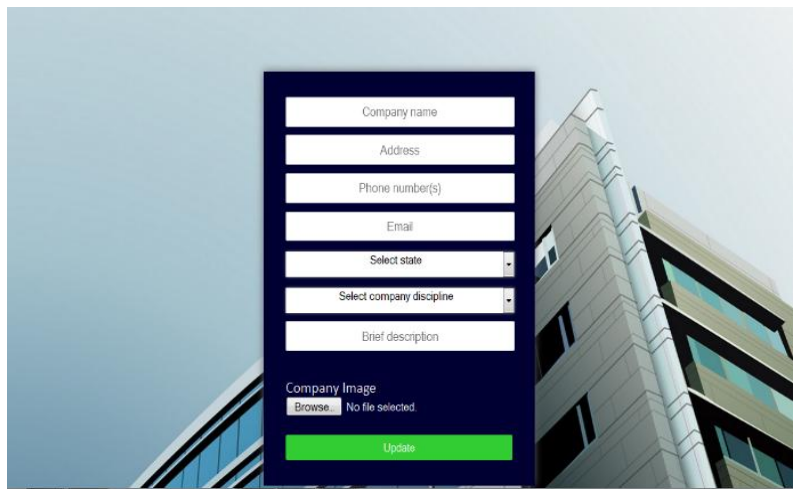

Figure 11: Admin Add-organization page

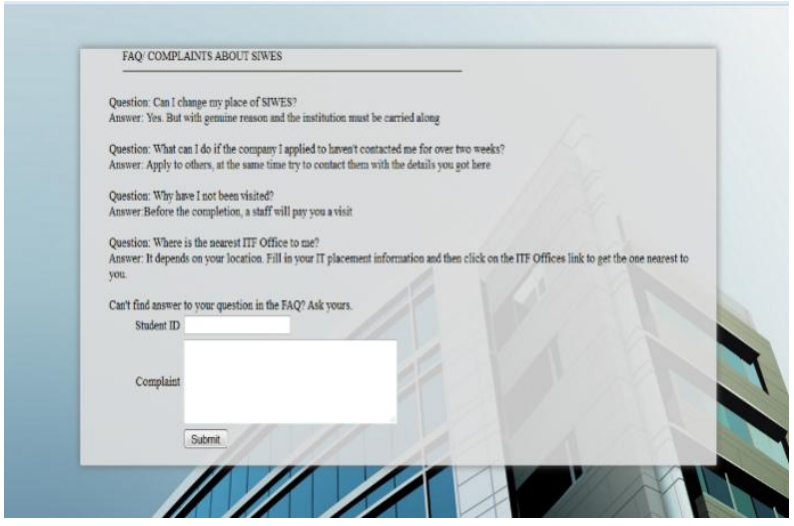

Figure 12: Students' Complaint page

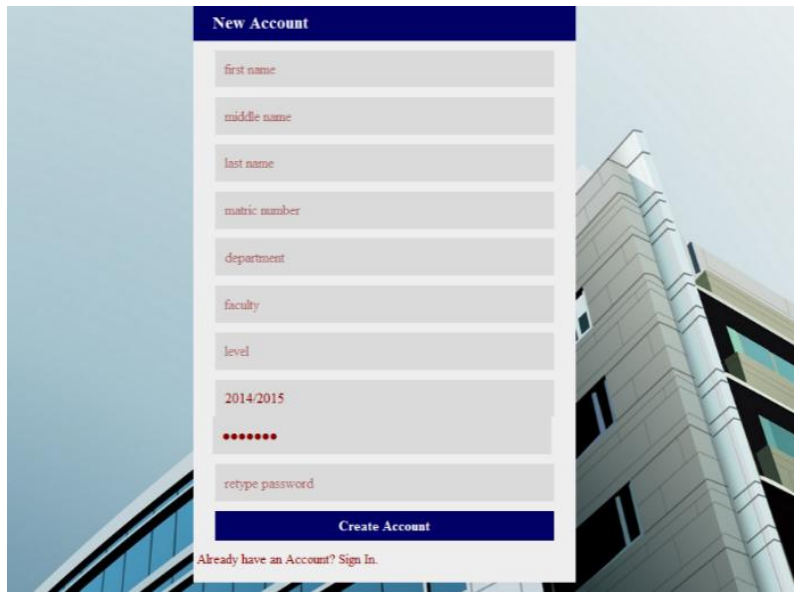

Figure 13: Users' Registration page

\section{CONCLUSION}

In this study, an architectural framework comprising models to be used for the development of a Mobile-based system for automatically recommending suitable placements for Industrial training for prospective students in Nigerian tertiary institutions particularly universities was proposed, taking the host institution of the study, Adekunle Ajasin University as a case study. The next process involved the development, debugging and deploying the mobile application for this system. When fully utilized, it will go a long way in alleviating the pains Nigerian students currently experience in seeking for suitable placements for the mandatory Industrial training, which is a requirement for all students before they can graduate. In the future, this would have to be extended to include more disciplines, not offered in the case study institution, covering more locations and narrowed to even include organizations with specific areas of specializations within the disciplines considered and also available as a webbased system.

\section{ACKNOWLEDGEMENT}

Special thanks goes to the SIWES Unit of Adekunle Ajasin University, Akungba-Akoko especially Engineer Seyi Osanyibi for providing us with the relevant data of the placements of students over the previous academic sessions, which we used to populate the database for this research work

\section{REFERENCES}

[1] Akerejola, O. (2008): Information and Guidelines for Student Industrial Work Experience Scheme available: http//www.itf_nigeria.org/docs/SIWES_of_guide_pdt 
[2] Alabi (2009): Assessment of SIWES Relevance to Business Education Programme Objectives. Available at Nairaproject.com/m/projects/665.html

[3] C. U. Ekwunke (2008) Strategies for Improving Manpower Production in Vocational Technical Education in Nigeria: Global journal of educational research Vol. 7, No. 1\&2 pg. 2.

[4] Chijioke F. Ugwuanyi , Jonas U. Ezema (2014): "Challenges of Industrial Training on the Performance of Business Education Graduates".

[5] Emmanuel Adetiba, Victor O. Matthew et.al. (2012) "Development of e-SIWES portal: A web based Platform for student Industrial Work Experience Scheme (SIWES) Management". Published at International Journal of Application Information Systems (IJAIS). http://esiwes.covenantuniversity.edu.ng.

[6] Eze, N. M (1998), Industrial Work Experience: A Medium for actualization vision 2010 through Home economics education. Journal of women in College of Education, pp. 154-160.
[7] Fabrizio Maria Maggi Class modelling (part1) Institute of Computer Science (these slides are derived from the book "Syllabus M.C.A. (Semester IV) Object-oriented modeling and design with UML").

[8] Industrial training handbook (2008) published by: Industrial Relating Committee, March 2008. (ITM, 2008): Industrial Training Manual (2008): School of Engineering and Science, Curtain Sarawak.

[9] Laird, R. J., \& Turner, C. R. (2008b, October).Interactive Web-based Placement Management -Principles and Practice using OPUS. Paper presented at ACEN-WACE Conference, Sydney, Australia.

[10] Mbata, A, (2000): Towards a More Effective Manpower, Training and Development in Technical Education. Lagos: Journal of Technical Education Board Review Vol. 2, No. 2 pp. 205

[11] Wodi, S.W and Dokuba (2009); A Appraisal of Student Industrial Work Experience Scheme (SIWES) in Five Tertiary Institutions in Rivers State, Nigeria; European Journal of Social Science, 2009. 